\title{
多結晶MnZn, NiZnフェライトの複素透磁率についての一考察
}

\author{
正 員 早乙女 英夫 (千葉大) \\ 正員榊陽 (千葉大)
}

\section{Complex Permeability of Polycrystalline $\mathrm{MnZn}$ and NiZn Ferrites}

Hideo Saotome, Member and Yo Sakaki, Member (Chiba University)

The complex permeability of ferrites is frequency dependent. The real part of the complex permeability deteriorates in a high frequency range and the imaginary part has a peak after staring the deterioration. This paper tries to reveal that the frequency characteristics for some ferrites can be approximately derived from a first-order linear differential equation for the magnetic field intensity and magnetic flux density. The first-order differential equation is expressed by the reciprocal of the complex permeability and provides first-order magnetic and electric circuits for ferrite cores. In contrast with the commonly used series $R s-L s$ circuit for the cores, obtained from $\boldsymbol{B}=(\boldsymbol{\mu} \cdot-\boldsymbol{j} \boldsymbol{\mu} ") \boldsymbol{H}$, the derived first-order electric circuit is composed of the inductance $(L)$ and resistance connected in parallel. In this paper, it is demonstrated that the inductance $L$ remains constant, whereas $L s$ decreases with the increase in frequency. In other words, the real part of the reciprocal of the complex permeability remains constant for the frequency increase. In addition, it is found that the imaginary part of the reciprocal of the complex permeability is approximately proportional to frequency.

キーワード : フェライト, 複素透磁率, スヌークの限界, 動的磁気損失, 鉄損

\section{1.まえ がき}

著者らは, Mn-Zn系およひNi-Zn系フェライトの同材質・ 異寸法のトロイダル磁心に対し，MHz帯までの鉄損の実測 および解析を行い，これらの比較から，従来より残留損失 として位置付けられている損失が磁心内の動的磁気損失で

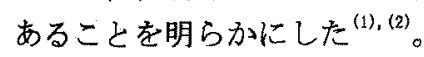

一方，従来よりフェライトの損失を表現するために用い られている複素透磁率 $\dot{\mu}$ は， $j=\sqrt{-1}$ として(本論文で は, $j$ 以外の複素数に上ドットを付けるものとする)

$\dot{\mu}=\mu^{\prime}-j \mu^{\prime \prime} \ldots \ldots \ldots \ldots \cdots \cdots \cdots \cdots \cdots \cdots \cdots \cdots \cdots \cdots \cdots$

と一般に表し $\left(\mu^{\prime \prime}>0\right)$, 磁束密度 $\dot{B}$ は, 磁界 $\dot{H}$ に対する時 間的な位相遅れを考慮して

$$
\dot{B}=\dot{\mu} \dot{H}=\left(\mu^{\prime}-j \mu^{\prime \prime}\right) \dot{H}=\mu^{\prime} \dot{H}-j \mu^{\prime \prime} \dot{H} \cdots \cdots(2)
$$

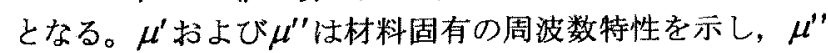
が極大となる周波数近傍より $\mu^{\prime}$ が周波数の增大とともに低 下し始め，低周波での $\mu^{\prime}$ が大きい材料は，この $\mu^{\prime} の$ 低下が 比較的低い周波数で生しることが知られている。 $\mu^{\prime}$ および $\mu^{\prime \prime}$ の周波数特性の測定を複数の異なる組成のNi-Zn系フェ ライトに対して行った結果において， $\mu^{\prime}$ が低周波での $1 / 2$ になる点を結んだものをSnoekの限界線と呼び,これは一 般に，自然共鳴によるものとして説明がなされている(3)〜(5)。 一方, 最近, フェライトにおけるこの $\mu^{\prime}$ の低下は, 自然共 鳴, 磁壁共鳴などの磁気特性としての 2 次系の共振現象で
はないとの考えを示した報告 ${ }^{(6)}$ が著者ら ${ }^{(7)}$ 以外によっても 行われてお゙りこの点の吟味を行う必要がある。

本論文では, いくつかのフェライト材に対し，動的磁気 損失を表すために導入した動的磁気損失パラメータにより 前述の $\mu^{\prime}$ の低下が説明できることを示し，これは共振現象 が顕著な 2 次系による特性とは異なることを示す。

\section{2. 複素透磁率と動的磁気損失パラメータ}

〈2・1〉襍素透磁率の測定 （2）式に磁心の磁路断面積 $A$ および磁心に施した励磁巻線の巻数 $N$ を乗じて時閒微分す る( $\omega$ を励磁角周波数として $j \omega を$ 乗ずる) と左辺は励磁巻線

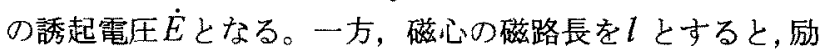
磁電流は $\dot{I}=\dot{H} l / N$ となり, さらにこの磁心に対して図 1 の $L_{s}-R_{s}$ 直列等価回路を仮定すると, $\dot{E}=\left(R_{s}+j \omega L_{s}\right) \dot{I}$

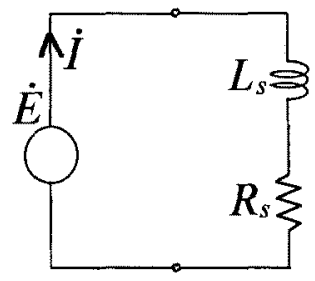

図 $1 \mu^{\prime}$ および $\mu^{\prime \prime}$ 測定時の電気等価回路

Fig. 1. Equivalent circuit for measuring $\mu^{\prime}$ and $\mu^{\prime \prime}$. 


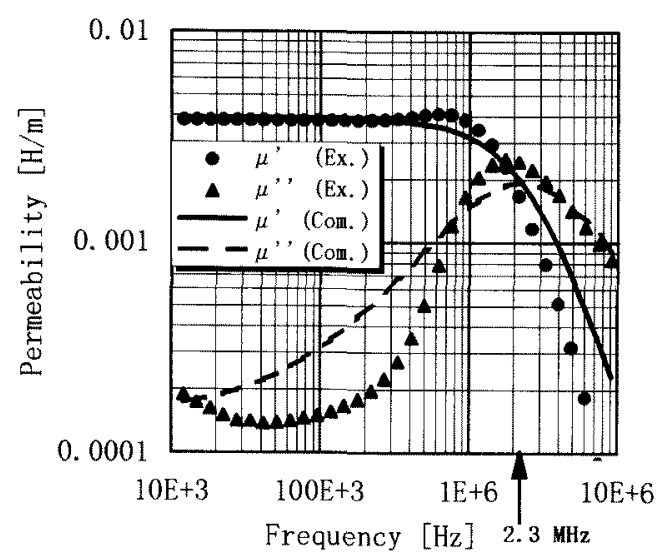

図 2 磁心No.10複素透磁率の周波数特性

Fig. 2. Frequency characteristics of the permeabilities for core No. 1 .

表 1 フェライト磁心No. 1, No.2およびNo.30特性 Table 1. Properties of cores No. 1 , No. 2 and No. 3.

\begin{tabular}{|c|c|c|c|c|c|c|}
\hline 磁心 & $\begin{array}{c}\text { 内径 } \\
{[\mathrm{mm}]}\end{array}$ & $\begin{array}{c}\text { 外径 } \\
{[\mathrm{mm}]}\end{array}$ & $\begin{array}{c}\text { 高さ } \\
{[\mathrm{mm}]}\end{array}$ & $\mu_{\boldsymbol{r}}^{*}$ & $\begin{array}{c}\lambda_{k 0}[\Omega / \mathrm{m}] \\
\text { at } 1 \mathrm{kHz}\end{array}$ & $\lambda_{f}[\Omega / \mathrm{m}]$ \\
\hline No. 1 & 5.0 & 10.0 & 2.5 & 3080 & 615 & 57000 \\
\hline No. 2 & 7.5 & 12.8 & 2.6 & 1900 & 240 & 29000 \\
\hline No. 3 & 15.0 & 25.0 & 4.5 & 2400 & 240 & 37000 \\
\hline
\end{tabular}

* 励磁磁束密度の波高值 $B_{m}=20[\mathrm{mT}]$ での測定估

より,

$$
L_{s}=\mu^{\prime} N^{2} A / l
$$$$
R_{s}=\omega \mu^{\prime \prime} N^{2} A / l
$$

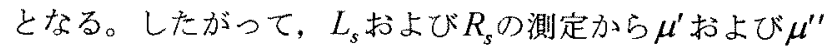
が求まる。フェライトメーカ一が提供する初透磁率 $\mu_{i}$ の周 波数特性力夕ログデータは, 通常，(3)式の $\mu^{\prime}$ 用いている。

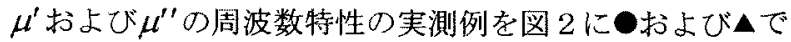
示す。図20の抢よびムは，表1に寸法および後述する媒 質パラメータの值を示したMn-Zn系フェライト磁心No. 1の $\mu^{\prime}$ おび $\mu^{\prime \prime}$ の周波数特性実測值を示すもので， $L_{s}$ および $R_{s}$ の測定にはインピーダンス/ゲイン・フェーズアナライザ （HP製4194A）を用いた。

〈2·2〉磁気損失を表す磁界方程式 (2)式は磁束密度 $\dot{B}$ 磁界 $\dot{H}$ と同相および $\pi / 2$ 遅れた成分, すなわち $\mu^{\prime} \dot{H}$ お よび $\mu^{\prime \prime} \dot{H}$ に分解したものであり，別な表現をすれば $\dot{B}$

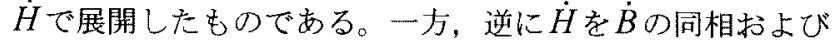
$\pi / 2$ 進み成分で展開すると,

$$
\dot{H}=\frac{1}{\mu_{0} \mu_{r}} \dot{B}+j \frac{\omega_{0}}{\lambda_{h 0}} \dot{B}+j \frac{\omega}{\lambda_{f}} \dot{B}
$$

と書ける ${ }^{(1),(2)}$ 。ここで， $\mu_{0}$ は真空中の透磁率， $\mu_{r}$ は比透磁 率, $\lambda_{h 0}[\Omega / \mathrm{m}]$ はヒステリシス損失を表すためのヒステリ シスパラメータ, $\omega_{0}[\mathrm{rad} / \mathrm{s}]$ は $\lambda_{h 0}$ 測定時の角周波数, $\lambda_{f}[\Omega / \mathrm{m}]$ は残留損失を動的磁気損失として説明するため

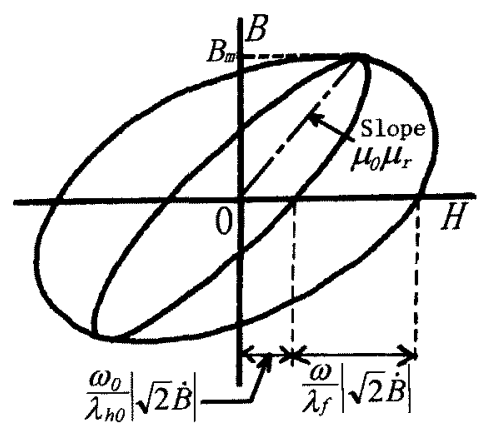

図 $3 B$-Hルーフ

Fig. 3. $B-H$ loop.

に導入した動的磁気損失パラメータである。図 3 は $B-H$ ループを示すもので，内側および外側のループはそれぞれ 低周波および高周波での $B-H$ ループである。ここで，低 周波とはフェライトのヒステリシス損失が鉄損に対して支 配的である周波数域である。（5）式右辺の各項を図 3 の

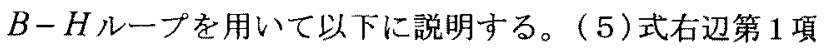
は $\dot{H} の \dot{B}$ に対する同相成分であることから， $\mu_{0} \mu_{r}$ は，図3 のB-Hループに执いて $B$ が最大となる点(このとき， $d B / d t=0$ で, $H$ は $B$ 対する同相成分の孙)と原点とを結

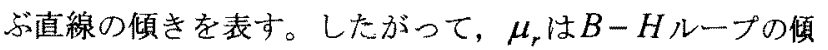
きによって定義される比透磁率(実数)である。（この $\mu_{r}$ は 実数であり，これは $\dot{\mu}_{r}=\dot{\mu} / \mu_{0}=\mu_{r}{ }^{\prime}-j \mu_{r}{ }^{\prime \prime}$ とは異なり， 「3.考察」の(1)で述べるように $\mu_{r}{ }^{2}$ とも異なる。）ま た，(5)式右辺第 2 項は $\dot{B} よ り ~ \pi / 2$ 位相が進んだ, 周波数 に依存しない磁界成分を表し，右辺第 1 項と第 2 項で図 3

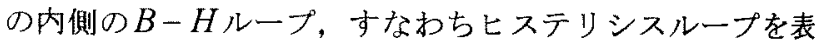
す。 $\lambda_{h 0}$ は，鉄損がヒステリシス損失のみとみなせる低周 波(角周波数 $\omega_{0}$ ) での複素透磁率より

$$
\lambda_{h 0}=\omega_{0}\left(\mu^{\prime \prime}+\mu^{\prime 2} / \mu^{\prime \prime}\right)
$$

によって求められる。また， $\dot{B}$ のきさを実効值とすると， $\left(\omega_{0} / \lambda_{\text {ho }}\right)|\sqrt{2} \dot{B}|$ は保磁力之なる。（5）式右辺第 3 項は励磁 周波数に比例して増加する, $\dot{B} よ り \pi / 2$ 位相の進んだ磁界成 分走しており，この磁界成分 $\left(\omega / \lambda_{f}\right)|\dot{B}|$ と磁束密度の時間 変化率 $\omega|\dot{B}|$ との積が励磁周波数の 2 乗に比例して増加する 動的磁気損失密度

$$
p_{f}=(\omega|\dot{B}|)^{2} / \lambda_{f}\left[\mathrm{~W} / \mathrm{m}^{3}\right]
$$

を与文, 1 周期当たりの動的磁気損失 $\left[\mathrm{J} / \mathrm{m}^{3}\right]$ 性, 図 3 の外 側のループの面積から内側のループの面積を差し引いた部 分に当たる。（5)式の媒質パラメータ值の例として，磁心 No. $10 \mu_{r}, \lambda_{h 0}\left(\omega_{0}=2 \pi \times 1000[\mathrm{rad} / \mathrm{s}]\right)$ および $\lambda_{f}$ (周波数 に無関係)の值 ${ }^{(1)}$ を表 1 に示す。ここで， $\lambda_{\text {h0 }}$ はヒステリシ スループの大きさに依存するが， $\mu_{r}$ 扝よび $\lambda_{f}$ は極めて微 小な励磁条件を除き, 磁束密度の非飽和の範囲で大きく変 動することはない(1),(2)。

(5)式に磁路長lを乗して起磁力 $\mathscr{F}$ とすると, 図4の磁

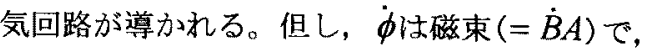




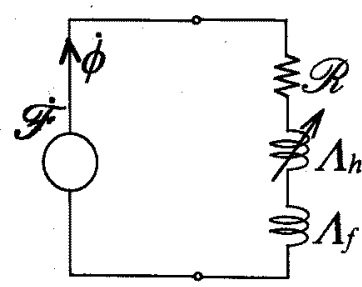

図 4 磁気損失を考慮した磁気等価回路

Fig. 4. Magnetic circuit taking account of the magnetic loss.

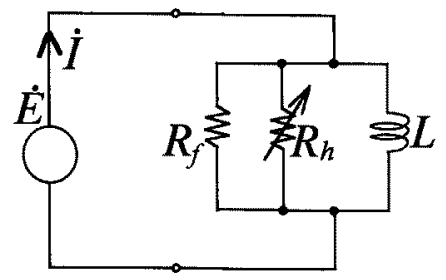

図 5 図 4 から導かれる電気等価回路

Fig. 5. Equivalent circuit derived from Fig. 4.

$$
\begin{aligned}
\mathscr{R} & =\frac{l}{\mu_{0} \mu_{r} A} \cdots \cdots \\
\Lambda_{h} & =\frac{l}{\lambda_{h 0}\left(\omega / \omega_{0}\right) A} \\
\Lambda_{f} & =\frac{l}{\lambda_{f} A} \cdots \cdots
\end{aligned}
$$

であり， $\Lambda_{h}$ は周波数の增加とともに減少する。図 40 磁気 回路は，磁心に励磁巻線(巻数 $N$ )を施したインダクタの電 気等価回路を与え，巻線抵抗を無視したときの印加電圧お

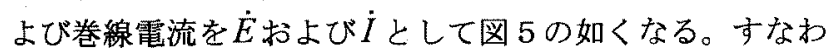

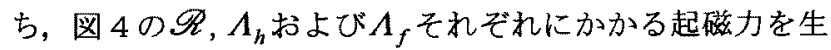
ずる電流 $\dot{I}$ の各成分は, 図 5 の $L, R_{h}$ おび $R_{f}$ それ゙れに 分流し, 図 4 之図 5 の各回路要素の関係は

$$
\begin{gathered}
L=N^{2} / \mathscr{R} \cdots \\
R_{h}=N^{2} / \Lambda_{h} \\
R_{f}=N^{2} / \Lambda_{f}
\end{gathered}
$$

となる。こご， $R_{h}$ は周波数の増加とともに増大する。図

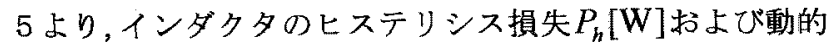
磁気損失 $P_{f}[\mathrm{~W}] は$, 電圧 $\dot{E}$ の大きさを実効值として, それ ぞれ

$$
\begin{gathered}
P_{h}=|\dot{E}|^{2} / R_{h} \\
P_{f}=|\dot{E}|^{2} / R_{f}
\end{gathered}
$$

となる。

以上より，(2)式は図 1 のインダクタンス一抵抗の直列 回路を与光 ${ }^{(4)}$, 一方, (5) 式は図 5 の並列回路を導くこと がわかる。

〈2·3〉フェーザ図による表示 (2) 式と (5) 式は, 同じ ことを互いに逆数の形で表現しているもので, 周波数特性

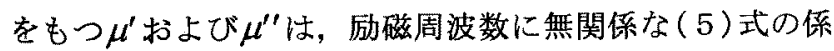

$\operatorname{Re}[\dot{\mu}]=\mu^{\prime}$

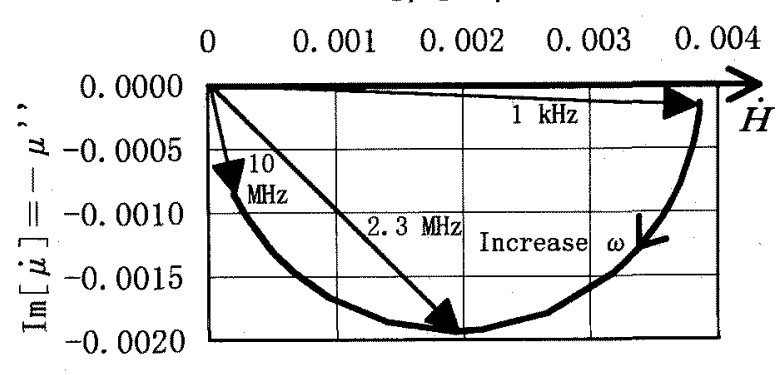

図 $6 \dot{\mu}$ のフェーザ図

Fig. 6. Phasor diagram of $\dot{\mu}$.

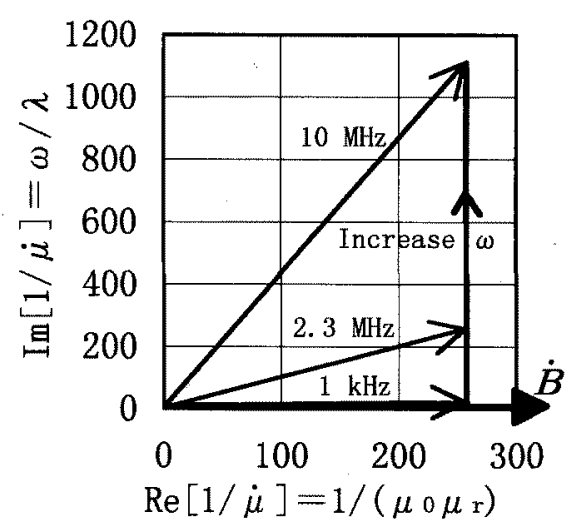

図 $71 / \mu$ 旧フェーザ図

Fig. 7. Phasor diagram of $1 / \mu$.

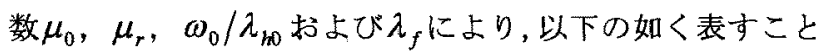
ができる。

$$
\begin{aligned}
& \mu^{\prime}=\frac{\mu_{0} \mu_{r} \lambda^{2}}{\omega^{2}\left(\mu_{0} \mu_{r}\right)^{2}+\lambda^{2}} \\
& \mu^{\prime \prime}=\frac{\omega\left(\mu_{0} \mu_{r}\right)^{2} \lambda}{\omega^{2}\left(\mu_{0} \mu_{r}\right)^{2}+\lambda^{2}}
\end{aligned}
$$

但し,

$$
\begin{aligned}
& \lambda=\frac{\lambda_{h} \lambda_{f}}{\lambda_{h}+\lambda_{f}} \\
& \lambda_{h}=\lambda_{h 0} \frac{\omega}{\omega_{0}}
\end{aligned}
$$

である。

表 1 に示した磁心No. 1 の $\mu_{r} ， \lambda_{h 0}$ および $\lambda_{f}$ の值を用いて (16) および(17) 式から $\mu^{\prime}$ および $\mu^{\prime \prime}$ の周波数特性を求める と図 2 の実線および破線の如くなり，ほぼ実测值と同様の 特性となった。すなわち， $\mu^{\prime \prime}$ が最大となる周波数近傍から の $\mu^{\prime}$ の低下を(5)式により表現できたことになる。一方， $\mu^{\prime \prime}$ の周波数特性に関しては, $100 \mathrm{kHz}$ 前後で実測值と計算值 に大きなずれがあるものの， $\mu^{\prime \prime}$ の最大值付近では両者はほ ぼ一致している。図2の実線掞よび破線の大ささを縦軸お

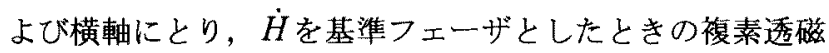
率 $\dot{\mu}$ の周波数軌跡 ${ }^{(3)}$ を図 6 に示す。図 6 より，周波数の増 
大とともに $\dot{\mu}$ の位相角, すなわち $\dot{B}=\dot{\mu} \dot{H}$ の位相角が開き, また， $\dot{B}$ と出の大きさが減少していくようすがわかる。一

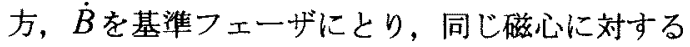

$$
\frac{1}{\dot{\mu}}=\frac{1}{\mu_{0} \mu_{r}}+j \frac{\omega}{\lambda}
$$

の周波数軌跡を描いたものが図 7 で, $\dot{H}=(1 / \dot{\mu}) \dot{B}$ の大きさ が周波数の増加とともに增大することがわかる。但し， 1/ $\boldsymbol{\mu}$ の実部は周波数によらず一定である。このことは， (8)および(11) 式から, 図 5 のインダクタンスLは周波数 に無関係に一定であることを意味する。すなわち，磁心は 高周波域においても変圧的な振る舞いをする。これは， 10MHz励磁での磁心No.1の鉄椇計測において, 励磁電圧に 対して巻数比に応じたサーチコイル ( 2 次巻線) 電圧が生ず るという実験事実と一致する。

\section{3. 考 察}

（1） $\mu^{\prime}\left(=\mu_{0} \mu_{\mathrm{r}}{ }^{\prime}\right)$ と $\mu_{0} \mu_{r}$ は低周波域でほぼ一致するが， $\mu^{\prime}$ は図 2 に示した通り周波数特性を持ち， $\mu_{r}$ は前述の如く 一定值として扱ってよい。そこで， $\mu^{\prime}$ と $\mu_{0} \mu_{r}$ の違いについ て考察する。図 $8(\mathrm{a})$ および(b)は，適当な基準つェーザ を設け, 磁界を $\dot{H}=H_{R}+j H_{l}$, 磁束密度を $\dot{B}=B_{R}+j B_{I}$ としたフェーザ図である。 $\mu_{0} \mu_{r}$ は「磁束密度と, これと同 相な磁界との比」として定義されており, 図8(a)より

$$
\mu_{0} \mu_{r}=|B| / H^{\prime}
$$

となる。一方， $\mu^{\prime}$ は磁界と，これと同相な磁束密度との 比の逆数」として定義されており,図8(b)より

$$
\mu^{\prime}=B^{\prime} /|H|
$$

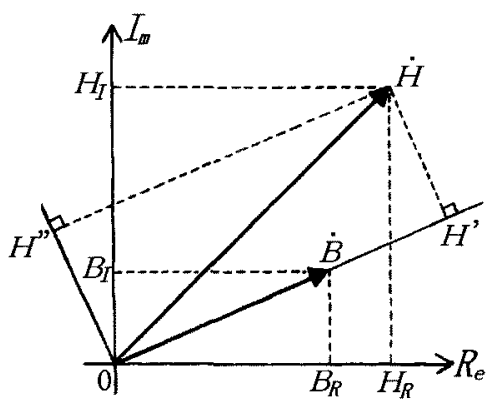

(a)

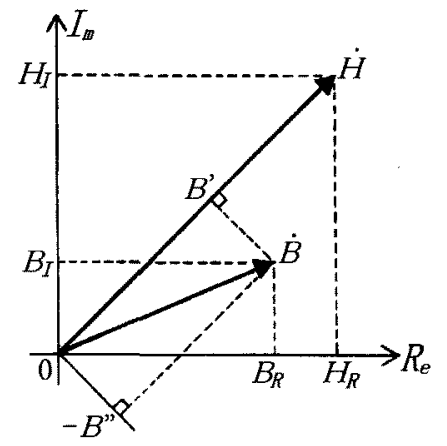

(b)

図 $8 \dot{H}$ 亡 $\dot{B}$ のフェーザ図

Fig. 8. Phasor diagram of $\dot{H}$ and $\dot{B}$.

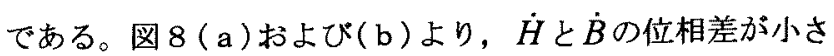
い低周波域では $\mu^{\prime} \cong \mu_{0} \mu_{r}$ (一定值) となることがわかる。 ま た，励磁周波数を増加させると $\dot{H}$ と $\dot{B}$ の位相差方増大寸る が,これは図8（a ）または(b)のどちらのフェーザ図でも 表現することができる。 $\mu_{r}$ が周波数に依らずに一定として 扱ってよいという実験事実は, 励磁最大磁束密度 $B_{m}$ (図 3 参照)一定条件において, 図 8(a)の $H^{\prime}$ が周波数に依らず に一定であることを意味し, 周波数とともに増加する成分 は同図の $H^{\prime \prime}$ み，すなわち，（5)式の虚数部(正確には右 辺第 3 項)のみである。

（2）図6の円楾図より， $\mu^{\prime \prime}$ が最大となる周波数では $\mu^{\prime}$ の值は低周波時の $1 / 2$ になり，この周波数を $f_{h}$ とする ${ }^{(8)}$ 。 また，この時 $\mu^{\prime}=\mu^{\prime \prime}$ となり，この条件より $f_{h}$ を求めると 次式の如くなる。

$$
f_{h}=\frac{1}{2 \pi}\left(\frac{1}{\mu_{0} \mu_{r}}-\frac{\omega_{0}}{\lambda_{h 0}}\right) \lambda_{f}
$$

例として, 磁心No. 1 場合, $f_{h}=2.3[\mathrm{MHz}]$ である。また, (23) 式は，(17) 式を用いて $\partial \mu^{\prime \prime} / \partial \omega=0$ より求めることも

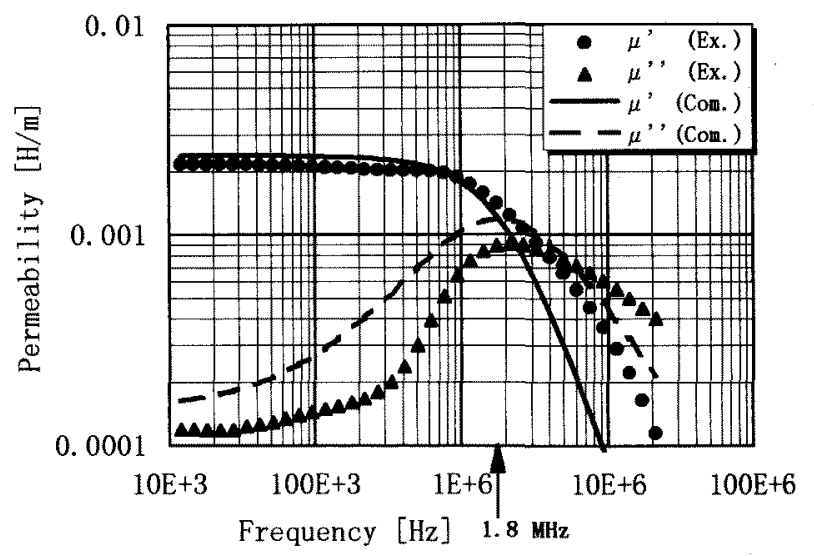

図 9 磁心No. 2 の複素透磁率の周波数特性

Fig. 9. Frequency characteristics of the permeabilities for core No. 2 .

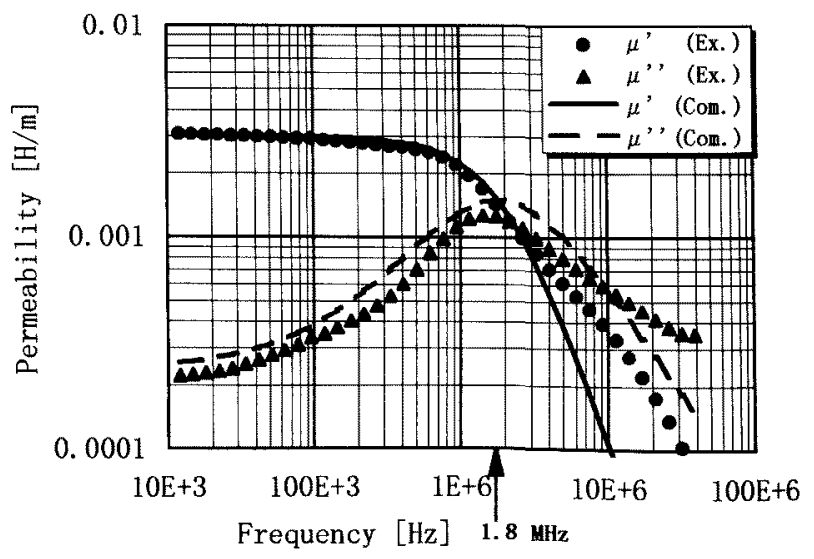

図10 磁心No. 3 の複素透磁率の周波数特性

Fig. 10. Frequency characteristics of the permeabilities for core No. 3 . 
できる。(23)式より, $f_{h}$ は動的磁気損失パラメータ $\lambda_{f} に$ 比例することがわかる。また, 同式右辺第 2 項は第 1 項よ り（例えば磁心No.1の場合約 1 桁）小さいので, $f_{h}$ は比透 磁率 $\mu_{r}$ にほぼ反比例し，このことは，従来より多くのフェ ライトに対して定性的に知られている実験事実と一致する。

（3）励磁周波数を增大させると，図 5 の $R_{f}$ が $\omega L$ に対 して相対的に小さくなり， $B_{m}$ 一定条件 $(|\dot{E}| \propto f)$ では，動 的磁気損失が $|\dot{E}|$ の 2 乗，すなわち周波数の 2 乗に比例して 增大するので((15)式, (7) 式参照)，インダクタ(または 2 次巻線を施した変圧器)をdutyの低いパルス用途とする か, 十分な磁心の泠却が必要となる。一方, 電圧 $\dot{E}$ 一定条 件では， $R_{f}$ は周波数に無関俰に一定であるので，(15)式の 動的磁気損失 $P_{f}$ は周波数によらずに一定である。

（4）図 9 および図10は，表1に示したNi-Zn系フェライ 卜磁心No. $2 お$ よびNo. 3 についての図 2 と同様の測定および 計算結果を示したもので，それぞれの $f_{h}$ もわせて記した。 これらの場合においても(5)式に表 1 の $\mu_{r}, \lambda_{h 0}$ および $\lambda_{f}$

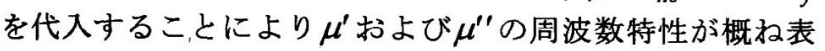
せることがわかる。

（5）動的磁気損失が支配的となる高周波域においては (5) 式右辺第 2 項は無視でき, $\dot{B}$ と $\dot{H}$ の関係は定数係数の 一階線形微分方程式によって表現できる。よって，(5)式

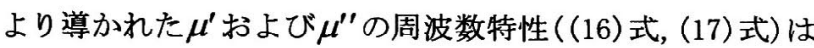
2 次系(共振形)ではなく，1 次系(緩和形) のモデルである。

\section{4. まとめ}

フェライトの複素透磁率は一般に周波数特性を持ち，そ の虚部の最大值付近から実部の大きさが周波数の増加とと もに低下する。本論文では，3 種のフェライト材に対して 複素透磁率の周波数特性を実測し，筆者らが提唱している 動的磁気損失パラメータを用いた磁束密度に関する一階線 形微分方程式により同様の周波数特性が得られることを示 した。また, この微分方程式は一次の磁気回路を与え, さ らにこれから抵抗・インダクタンスの並列電気回路が導か れ，このインダクタンスは周波数に依存せず一定であるこ とを示した。これは， $\dot{B}=\left(\mu^{\prime}-j \mu^{\prime \prime}\right) \dot{H}$ は抵抗ーインダク タンスの直列回路を導くが，このときのインダクタンスが 周波数特性を持つことと対照的である。換言すれば，複素 透磁率注周波数特性を持つが，その逆数の実部は定数であ り，虚部は近似的に周波数に比例するものとして扱えるこ とを示した。

(平成 8 年 8 月 26 日受付, 平成 9 年 1 月 20 日再受付)

\section{文献}

(1) H. Saotome, Y.Sakaki: "Iron loss analysis of $\mathrm{Mn}^{-}$ Zn ferrite cores", IEEE Trans. Magn. 33, $728 \sim$ 734, (1997)

（2）早乙女英夫・河井武志・柇陽：「動的磁気損失パラ メータによるフェライト磁心の鉄損評価」, 電学論 $\mathrm{A}$, 116, 559 565 (平8-6)

(3) J. Smith and H.P. J.Wijn: "FERRITES", 269, Philips Research Laboratories, The Netherlands (1959)

（4）太田恵造：「磁気工学の基礎 II 一磁気の応用一」, 363 , 共立出版 (1973)

（5）近角聡信：「強磁性体の物理(下）一磁気特性と応 用一」，323，裳華房(1984)

（6）後藤聡志・曾我直樹・河野貴史・藤田明・高城重彰 : $\lceil\mathrm{Mn}-\mathrm{Zn}$ フェライトの透磁率の周波数特性」, 第19回 日本応用磁気学会学術講演概要集, 263,（1995）

（7）早乙女英夫・榊陽：「スヌークの限界は共鳴現象に よるものなのか?」, 第19回日本応用磁気学会学術講 演概要集，272,（1995）

（8）早乙女英夫・榊陽：「複素透磁率実部の周波数特性 によるフェライトの鉄損推定」, 電学論 $\mathrm{A}, 116$, 1027〜1028 (平8-11)

早乙女 英夫（正員）1958年12月13日生。1983年 3 月法 政大学大学院工学研究科博士前期課程修 了。同年 4 月富士電機 (株) 入社。(株) 富 士電機総合研究所勤務。1994年 3 月法政 大学大学院工学研究科博士後期課程修了。 同年 6 月千葉大学助手。1995年 9 月同大 学助教授となり, 現在に至る。主として, 電磁界系逆問題, 磁性材料の鉄損解析, 無効電力補償制御 および新しい磁気アクチュエータに関する研究に従事。 博士(工学)。IEEE, 日本応用磁気学会会員。

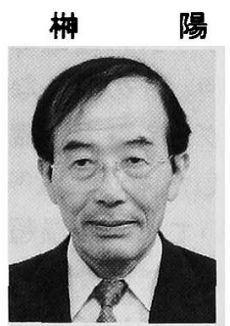

（正員）1932年 3 月 9 日生。1954年 3 月茨 城大学工学部電気工学科卒業。新電元工 業(株) ほか勤務の後, 1965年 3 月東北大 学大学院工学研究科電気及び通信工学専 攻修了。東北大学助手を経て, 現在, 千 葉大学教授。主として, 磁性材料の動的 磁化機構の解析と高周波電力損発生機構 の解明, 高周波磁気計測, 磁気応用デバイスの開発, 回遊 魚の磁気コンパス説の検証などに従事。工学博士。電子情 報通信学会, 日本応用磁気学会, IEEE, 日本水産学会会員。 